Article

\title{
Influence of Climate and Economic Variables on the Aggregated Supply of a Wild Edible Fungi (Lactarius deliciosus)
}

\author{
Oscar Alfranca ${ }^{1, \dagger}$, Roberto Voces ${ }^{2, \dagger}$ and Luis Diaz-Balteiro ${ }^{2, \dagger, *}$
}

1 Department of Agribusiness Engineering and Biotechnology, Technical University of Catalunya, Building D4-C, Esteve Terradas, 8, 08860 Castelldefels, Spain; E-Mail: oscar.alfranca@upc.edu

2 Department of Forestry Economics and Management, Technical University of Madrid, ETS Ingenieros de Montes, Ciudad Universitaria s/n. 28040 Madrid, Spain;

E-Mail: vocesr@gmail.com

$\dagger$ These authors contributed equally to this work.

* Author to whom correspondence should be addressed; E-Mail: luis.diaz.balteiro@upm.es; Tel.: +34-913-364-296; Fax: +34-915-439-557.

Academic Editor: Douglas L. Godbold

Received: 25 March 2015 / Accepted: 29 June 2015 / Published: 6 July 2015

\begin{abstract}
A mycological supply function of wild edible fungi is determined by a set of forest and economic variables, among which climate variables stand out. Focusing on wild mushroom picking with commercial value (Lactarius deliciosus (L.) Gray) as an example, the main objective of this paper is to obtain empirical evidence about the impact of meteorological and economic variables on the mushroom supply. A multidisciplinary vector error correction (VEC) model for mushroom supply is estimated. Coefficients for the Error Correction Term (ECT) are all significant, at the 0.01 significance level, both in the model for prices and for collected mushrooms. The value of the ECT coefficient in the equation for prices is -0.086 ( $t$-value: -9.321 ), and for the collected mushroom equation is 0.499 ( $t$-value: 3.913). The impact of precipitation on price changes is -0.104 ( $t$-value: -1.66 ), and the impact of temperature on mushroom harvest picking is 0.605 (t-value: 3.07$)$. We find that including climate factors to explain mushroom supply considerably strengthens the explanatory power of the model, and in some cases greatly changes the results.
\end{abstract}


Keywords: edible fungi; Lactarius deliciosus; rainfall; temperature; mushroom price; causality

\section{Introduction}

During the past few years, in numerous countries there has been an increase in the demand for some non-timber products from forests, edible wild mushrooms being a clear example of this trend [1,2]. As a result, harvesting of wild mushrooms increased starting in the 1980s [3]. Thus, following some authors, the value of worldwide edible and medicinal mushroom sales in 2003 was three times higher than in 1994 [1]. In support of this, in recent years many studies have appeared that attempt to link aspects related to the conditions of the site (ecological, climatic, etc.) to decisions associated with the management of those products. However, from an economic point of view, the studies in this respect are somewhat scant, in spite of several favorable circumstances: the high value of commercialized edible mushrooms [4], the huge economic importance associated with their consumption [5], the sharp increase in their demand during the last 40 years [6], and their economic potential in some countries, such as in the Mediterranean [7]. Thus, in some studies on the saffron milk cap demand in Spain, social and cultural variables (mainly the geographical origin of families), is considered to characterize mushroom consumption. The elasticity of this social variable is positive and clearly significant [8], while some estimate the economic value per year of edible and marketable mushrooms in Catalonia (Spain) [9]. Besides, under different perspectives, the value chain of wild edible mushrooms has been analyzed in several countries [10-14], while other studies deal with the economic valuation of recreational activities such as mushroom picking [15].

When characterizing mushrooms as a wild food, both at a local and aggregated level, it is necessary to take into account a heterogeneous set of variables, among which are climatic factors. Leaving aside parameters associated with their picking, numerous authors have written about different factors interacting with each other and which, to a certain degree, can explain larger or smaller harvests of edible fungi both in time and space. Without wishing to be exhaustive, we could talk about aspects associated with the stands sustaining the fungal population, and we thus find ourselves with factors associated with tree species and their age [16-18], with the silviculture practiced in these stands [19,20], or with edaphic conditions [21]. However, one of the most important factors - and which is considered in most of the works that aim to estimate what variables can account for the abundance, diversity, or commercial harvesting of certain mushrooms - would be climate variables. Nevertheless, these factors cannot completely explain the fructification of mushrooms [20], although in some cases they are good predictors of the presence of mushrooms [22]. Moreover, some authors state that the annual fluctuations in harvesting are due to both macro- and microclimatic conditions [23].

Given that a high percentage of the weight of fungi is composed of water, any climate or microclimate factor that increases or decreases the availability of water for the mushrooms will have an influence on their fructification [24,25]. It seems obvious that rainfall amount and timing would have an important role in mushroom picking prediction. Numerous studies have analyzed the effects of precipitation on the 
harvesting of different mushroom species [9,26-28]. However, other authors indicate that the most important variable is not precipitation, but the water retained in the soil [29].

The other climate variable usually considered when accounting for the existence of both epigean and hypogean fungi is temperature. Different explanatory variables have been used to obtain relationships between temperature and the mushrooms present in a specific area. Some studies have selected mean temperature data throughout the year [29], while other authors have selected the mean temperature of the site or of the months when the fructification is produced [26]. Finally, at a microclimatic level, aspect, slope, and exposure play an important role in the harvesting of mushrooms [30,31].

The studies mentioned above have one common characteristic: none of them has attempted to link the climate variables to the supply of some mushroom species of a marked commercial nature. References regarding the supply of mushrooms at the country or regional level are usually indirect [32], or are made to studies analyzing wild food as an ecosystem service [33].

The main objective of this paper is to characterize an aggregated supply function for a mushroom species, with the saffron milk cap serving as an example. For this, basic data from markets (quantity and prices) have been used. In this characterization, the geographical origin has been considered to recognize which factors determine the amount of supplied mushrooms. In order to develop this task, the largest national market of edible mushrooms has been considered: the Barcelona Central Market (Mercabarna). It should be pointed out that the saffron milk cap is one of the most popular mushrooms in Spain with the commercial market at a mean of nearly 500 tons a year [6], and Mercabarna is the principal market for this product $[34,35]$. It is also essential to point out that this analysis is developed with aggregated data from this market, and not with data closer to direct forest harvesters.

In relation to the mushroom market, there is no detailed information available on the value chain of these goods, which is a usual trend in these studies, save for a few exceptions [14]. In other words, it is not possible to break down all the costs associated with the commercialization of these products until they reach a central market. Besides, this is a product that is basically obtained from a picking exercise; neither the owner of the land nor, usually, the buyer has to make any outlay in order to optimize it. Therefore, a basic hypothesis of this work makes some sense: the supply function can be defined by means of the use of certain proxy variables that can adequately describe the way these middlemen act.

Interregional impacts of climate variables on mushroom picking are also analyzed in this paper, jointly with changes in the behavior of the mushroom supply. It could be easily accepted that favorable climate conditions could increase the supply of edible mushrooms for any given amount of inputs used. However, the relationships between climatic variables (such as precipitation and temperature) may not be so easy to explain, especially when other determinant factors are considered [29].

A main hypothesis of this paper is that, regarding mushroom markets, this supply relationship could be modified, for instance, by variables such as temperature and rain. In addition, these links are difficult to identify when the analysis is developed under an interregional perspective (something that can be found easily in mushroom markets). Hence, our hypothesis is that some regional relationships exist between temperature and rain, and that these variables, jointly considered, are determinants in the aggregated supply of some wild edible fungi such as saffron milk caps. 


\section{Experimental Section}

This part of the paper is divided into two sections. In the first, data and sources are described. In the second, the methodology which is applied for the empirical use of data is introduced and briefly discussed. The main interest of this section relies on the justification for the use of cointegration techniques in the analysis of the mushroom supply.

\subsection{Material}

The climate values used were obtained from a group of weather stations that, in representative numbers and distribution at a provincial level, have been selected based on their localization with respect to pine forest stands, and on the existence of a set of data necessary for calculating the variables chosen. Namely, it is assumed that the saffron milk caps are basically associated in the northern hemisphere with trees of some species of the genus Pinus [36]. Specifically, in diverse areas in Spain the greatest yields have been observed in Pinus sylvestris stands [35], whereas in other regions whose habitats are more favorable for the growth of other pine species, the saffron milk cap is found in Pinus halepensis, Pinus nigra, and Pinus pinaster stands, and with a lesser production in some scrublands and Quercus spp. stands [37]. For that reason, given the representative nature of pine trees in Spain, it has been assumed that the saffron milk cap harvest arriving at Mercabarna comes exclusively from pine stands. So, weather stations located within pine stands with a canopy cover higher or equal to $20 \%$, or no further than $2 \mathrm{~km}$ away from the pine forests, were selected. This spatial selection was made by means of a Geographic Information System (ArcGIS 9.2), taking information from the Spanish Forestry Map (SFM). In all, the climate data from 156 weather stations corresponding to the 12 provinces being analyzed were examined. In the interval analyzed (2002-2007) these provinces supplied on average $52.3 \%$ of the volume of saffron milk caps commercially available in Mercabarna over the six years, and as high as $85 \%$ in 2006. These weather stations are shown in Figure 1.

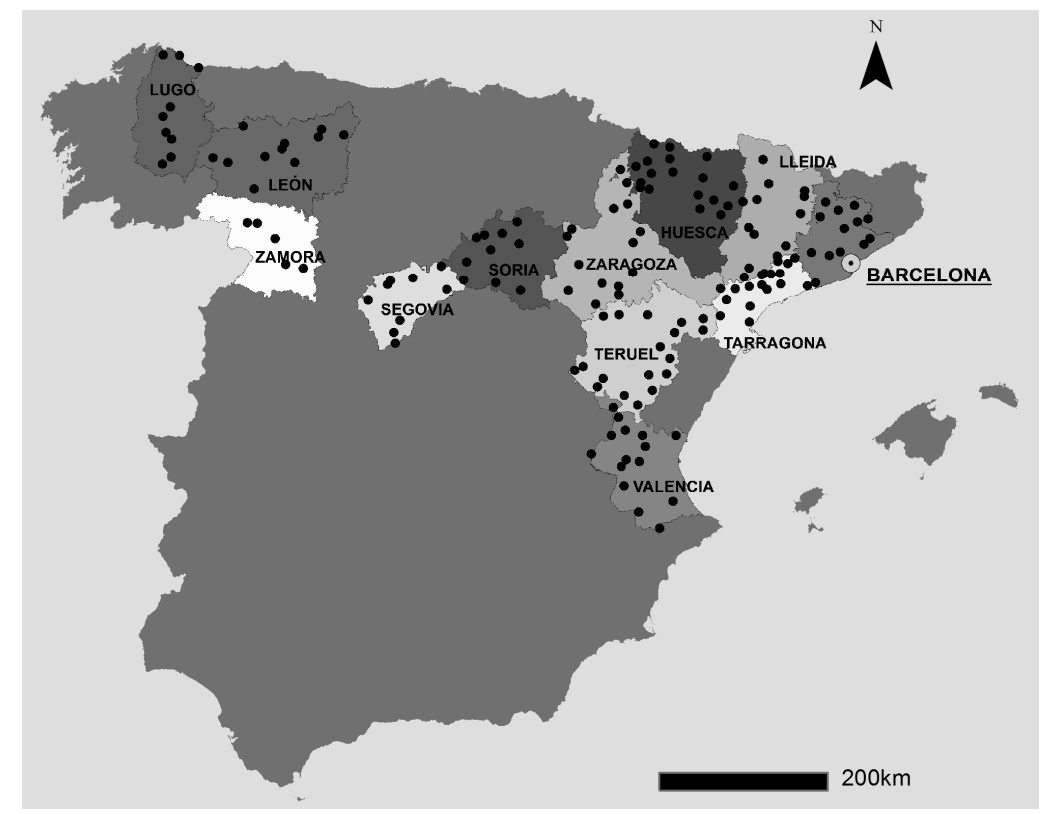

Figure 1. Map with the weather stations considered in this study. 
The weather stations in the provinces with complete time series on daily precipitation and daily maximum and minimum temperature during the period analyzed were first considered. In order to achieve the necessary representativeness for each province, several series with incomplete data (always less than 5\%) were completed using the means of the data of the rest of the years of the series. The climatic data used in this study were provided by the AEMET (Spanish National Meteorological Agency). All climatic variables were calculated weekly for the mycological seasons in the period from 2002 to 2007. Taking into account that each of these seasons lasted 26 weeks (July to December), the number of climatic data points processed was enormous, exceeding 511,000 values. In order to obtain a single weekly value of the above variables, a provincial average was calculated of the data corresponding to the different weather stations, weighting the results annually based on the relative importance of each province as the origin of the saffron milk caps arriving at Mercabarna. Finally, for each week of the mushroom season, both the price of saffron milk caps and the amount of saffron milk caps commercialized in Mercabarna have been computed. These weekly data have been supplied by the Barcelona Central Market itself. It should be pointed out that the real prices of each season have been used, taking 2002 as a base year.

\subsection{Methods}

This section presents an applied methodology to formulate a wild edible mushroom supply function. In this function, we need to take into account the fact that if prices increase, mushroom picking will also increase. This result is called the law of supply [38]. A mushroom supply function reflects the portion of their harvest that mushroom gatherers are willing to sell, at a given price, when all other factors (such as the weather, land conditions, or biodiversity) are held constant. In the following section, the methodology for the selection of variables for a mushroom supply function is introduced, and the variables and sources are described. Next, the statistical estimation methodology is exposed and justified.

\subsubsection{Selection of Variables}

In spite of the fact that mushroom harvesting processes have been widely analyzed in scientific studies $[35,39,40]$, it is much more difficult to find research on the economic and social supply conditions for wild edible fungi. In fact, we could accept that no general theoretical framework exists to explain the behavior of wild edible fungi markets, and more specifically for saffron milk caps. This point is particularly relevant because it can determine the methodology to enlighten the way mushroom supply works and, consequently, the way mushroom gatherers make decisions.

Given that no clear theoretical basis was found to explain the way mushroom supply works, we have decided to follow a wide general framework to estimate the supply function. From this, we select not only those variables that have commonly been found in the scientific literature (factors that influence the fructification of edible mushrooms), but also those variables associated with mushroom harvesting professional activities. All these variables are accepted, a priori, as potential determinants of mushroom supply (Table 1).

Therefore, first we considered a group of climatic variables, such as those related to temperature and a second group related to rainfall. Regarding economic variables that could determine the supply for saffron milk caps, the same methodology was applied, and some variables were selected in order to 
measure both the amount of saffron milk caps and the weekly price of the saffron milk caps in this central market.

Table 1. Variables used in the statistical models.

\begin{tabular}{ll}
\hline \multicolumn{2}{c}{ Climate Variables } \\
\hline Mean weekly temperature & tmed \\
Minimum weekly temperature & tmin \\
Mean weekly rainfall & rainfm \\
Weekly accumulated rainfall & rainfw \\
Weekly accumulated rainfall during the summer & rainfs \\
Rainfall of previous year & rainfpy \\
Potential evapotranspiration & pet \\
Difference between accumulated rainfall and potential evapotranspiration & diff \\
\hline \multicolumn{1}{c}{ Economic variables } & \\
\hline Weekly amount of saffron milk cap commercialized & lactkg \\
Weekly price of saffron milk cap & lactpr \\
Weekly price of saffron milk cap, with a delay of 1 week & dlactprw1 \\
Weekly price of saffron milk cap, with a delay of 2 weeks & dlactprw2 \\
\hline
\end{tabular}

\subsubsection{Climate Variables}

Climate variables have always been considered to be a decisive vector that, starting from some favorable conditions of vegetation and soil (among other variables), can account for the higher or lower level of picking of saffron milk caps in certain forests. Thus, it is necessary to use weather data, usually measured as a proxy for the temperature and moisture in the soil. This approach has commonly been used to examine different aspects related to mycological harvesting [41]. Beginning with temperature, the mean weekly temperature (tmed) and the minimum weekly temperature (tmin) were used as explanatory variables. To calculate these weekly means, the data relative to the daily maximum and minimum temperatures were noted in order to obtain the means of the weekly maximum and minimum temperatures. In addition to the temperature, another key factor in the fructification of the mycorrhizal fungi is water availability. Rainfall variables include mean weekly rainfall (rainfm), weekly accumulated rainfall (rainfw), weekly accumulated rainfall during the summer (rainfs), and the previous year's rainfall (rainfpy). For the first two variables the same methodology as in the case of temperature was followed. The rainfall accumulated only during the summer was taken as a variable, i.e., a dummy variable whose calculation covers the month of July and the first weeks of August, assigning a value of 1 if it exceeded the mean of the six years studied, and a value of 0 if not. Finally, the previous year's rainfall has been taken as a dummy variable with the aim of analyzing the existence of certain annual discontinuities in saffron milk cap yields [23]. It has been defined as a dummy variable with a value of 1 if the previous year's rainfall was lower than the mean, and with the value of 0 if not. To take into account soil moisture, two variables were used: potential evapotranspiration (pet) and the difference between accumulated rainfall and potential evapotranspiration (diff). For the calculation of the weekly mean potential evapotranspiration, the Thornthwaite experiment formula was used [42]. 


\subsubsection{Economic Variables}

In order to characterize the commercialization of mushrooms in Mercabarna, two variables have been incorporated that measure both the amount of saffron milk caps (lactkg) and the weekly price of the saffron milk caps (lactpr) in this central market. An important issue when approaching this type of model is the impossibility of storing the fresh product. Both price and mushroom harvesting are introduced in the supply function equation in logs, in order to reduce the risk of heteroskedasticity and linearize the supply function, so that coefficients could be assimilated to elasticities at the mean (see the Appendix for a brief analysis of this proposition).

With this approach, we are assuming a market for wild mushrooms without subjecting the products to any type of industrial process for their commercialization. Under these conditioning circumstances, the producers should have up-to-date information in order to make their picking decisions. This implies that there can only exist a minimal delay from when the decision is made to send the mushrooms to Mercabarna until they arrive at their destination. So, the repercussion of the price of the saffron milk caps in preceding weeks on the amount supplied of saffron milk caps was also included in the analysis. For this purpose, two variables have been considered. The first reflects the mean price of this mushroom in the previous week (dlactprw1) and the other, two weeks (dlactprw2) prior to the week analyzed. It is assumed that increases in price (lactpr) will cause increases in the amount supplied.

\subsubsection{Statistical Estimation Methodology}

A mushroom supply function describes the relationship between mushroom harvesting and mushroom prices. In order to improve the representation of this function and complete a mushroom supply function with all variables that could improve the explanation of this process, we have followed the well-known General-to-Specific method (see [43,44] for further developments).

The variable selection process is based on the Hendry method for selection process [45]. From this, we define a universe with all variables (both explaining variables and the dependent variable (see Table 1)), which implies the existence of $2^{11}$ possible models.

The most relevant hypothesis to represent mushroom supply is the positive relationship between prices and mushroom picking. Given that this hypothesis is commonly satisfied in mushroom markets, this idea induced us to consider statistical cointegration methods as an adequate estimation technique for mushroom supply. In this model, two variables (such as mushroom price and mushroom harvesting) are said to be cointegrated if a linear combination of them is stationary. So, we start with a very simple supply function, which reflects a cointegrating relationship between mushroom prices and harvesting:

$$
\text { lactpr }_{t}=\text { Blactkg }_{t}
$$

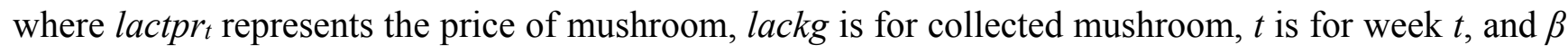
reflects the incidence of changes of lactkgt on lactpr.

Stationarity is when the statistical characteristics of a series such as its mean and variance remain constant, and also that covariance remains finite and constant for all periods across time (see Appendix for a more detailed explanation of these statistical concepts). In order to test the stationarity between mushroom harvesting and mushroom prices, we calculated the Augmented Dickey-Fuller (ADF), the 
Phillips-Perron (PP), and the Kwiatkowski-Phillips-Schmidt-Shin (KPSS) tests. Definitions and brief descriptions of the applied tests can be found in the Appendix.

The concept of cointegration is essential to the understanding of a mushroom supply function because it reflects the intuition that mushroom prices and mushroom harvesting would not drift too far apart from each other over time, even with the existence of external shocks like changes in weather conditions or temporary changes in public regulations on mushroom picking. Cointegration tests, such as the trace test and the eigenvalue test, are applied to test for the existence of a relationship between the two main variables of the mushroom supply function, and are briefly described in the Appendix. Evidence of cointegration implies the existence of causality between the two variables, at least in one direction. Therefore, we employ vector error correction (VEC) models in order to detect the direction of causality. Although there is a huge amount of literature estimating vector error correction models, there is not so much published research applying this statistical technique to non-timber forest products. One paper investigated the existence of any cointegration relationship and causality effects between price series of non-timber forest products, using VEC models [46]. These were applied using a price series of non-timber forest products in two markets in the Bankura district, in the state of West Bengal. A main conclusion of the paper is that there exists uniformity of price structure for collectors in almost all markets by different consumers for the same period. It also concludes that village wholesalers serve as the most important marketing agent of sample collectors, and pay the highest price to the collectors in all markets.

Mushroom prices are considered to determine in the Granger sense the size of the mushroom harvest, whenever the value of prices can be predicted more accurately by using past values on harvesting. VEC models are useful because they can distinguish between a long-term and a short-term relationship between variables, and can identify sources of causation that cannot be detected by the usual Granger causality tests. Permanent shocks are identified with long-run changes in the literature (that is, a cointegrating relationship), whereas transitory shocks (error correction term and independent variables in a VEC model) are identified with short-run modifications.

If cointegration is detected between mushroom prices and mushroom harvesting, there is a long-run relationship between them. Furthermore, the short-run dynamics can be described by the error correction model. This is known as the Granger representation theorem. This theorem implies that both mushroom prices and mushroom harvesting may be considered to be generated by two error correction models in the form:

$$
\begin{aligned}
& \text { (I) } \Delta \text { lactpr }_{t}=\beta_{1} E C T_{t-1}+\beta_{12} \Delta \operatorname{lactkg}_{t-1}+\beta_{13} \Delta \operatorname{lactkg}_{t-2}+\beta_{14} \Delta \operatorname{lactpr}_{t-1}+\beta_{15} \Delta \text { lactpr }_{t-2}+ \\
& +\beta_{16} \text { rainfm }_{t}+\beta_{17} \text { tmed }_{t}+u_{t} \\
& \text { (II) } \Delta \text { lactkg }_{t}=\beta_{2} E_{C C T_{t-1}}+\beta_{22} \Delta \text { lactkg }_{t-1}+\beta_{23} \Delta \text { lactkg }_{t-2}+\beta_{24} \Delta \text { lactpr }_{t-1}+\beta_{25} \Delta l a c t p r_{t-2}+ \\
& +\beta_{26} \text { rainfm }_{t}+\beta_{27} \text { tmed }_{t}+w_{t}
\end{aligned}
$$

where lactpr and $_{\text {lactkg }}$ represent the price of mushrooms and mushroom harvesting, respectively; $\Delta$ lactpr $_{t}$ and $\Delta \operatorname{lactkg}_{t}$ are the differences in these variables that capture their short-run disturbances (with one week of delay, and with two weeks of delay correspondingly); rainfm is the variable for the mean weekly rainfall; the tmed variable is for the mean weekly temperature; $u_{t}$ and $w_{t}$ are the serially uncorrelated error terms; and the error correction term $(E C T)$ is derived from the cointegration relationship and measures the magnitude of the past disequilibrium. In our case, the ECT is one such as 
$\left(\ln \left(\right.\right.$ lactpr $\left._{t-1}\right)-\beta \ln \left(\right.$ lactkg $\left.\left._{t-1}\right)\right)$. Coefficients for the ECT in Equation (2.I) is $\beta_{1}$ and coefficient for ECT in Equation (2.II) is $\beta_{2}$. These coefficients represent the deviation of prices and harvesting from the equilibrium in each of the equations so that, if no deviation exists, the $E C T$ is equal to zero.

This representation allows for causality to emerge in two ways. First, it allows for testing the significance of coefficients $\beta_{1}$ and $\beta_{2}$. A VEC model is set up for investigating both short- and long-run causality. In Model I (Equation (2)), the joint significance of $\beta_{12}$ and $\beta_{13}$ indicates that changes in mushroom prices are responding to short-term shocks in harvesting; the joint significance of $\beta_{14}$ and $\beta_{15}$ indicates that changes in mushroom prices are also determined by the lagged values of these mushroom prices and also by the effects of meteorological variables such as rain $\left(\beta_{16}\right)$ and temperature $\left(\beta_{17}\right)$. In Model II (Equation (2)), the joint significance of $\beta_{22}$ and $\beta_{23}$ indicates that variations in mushroom harvesting are dependent on short-term shocks in production; the joint significance of $\beta_{24}$ and $\beta_{25}$ indicates that changes in mushroom harvesting are also determined by the lagged values of differences in mushroom prices. Fluctuations in mushroom picking can also be explained by the effects of meteorological variables such as rain $\left(\beta_{26}\right)$ and temperature $\left(\beta_{27}\right)$.

From this, we could check whether the two sources of causation are jointly significant to test the Granger causality. In the price equation (Model I in Equation (2)), this implies that we test whether both harvesting and market deviations could have a joint influence on pricing. In the harvesting equation (Model II in Equation (2)), this implies that we test whether both prices and market deviations could have an influence on harvesting. This joint test could be an indicator of which variable bears the burden of short-term adjustment following a shock to the system, to re-establish long-term equilibrium.

In the equilibrium, $E C T_{t-1}$ will be equal to zero. Nevertheless, if some deviation from this path exists in the mushroom market, then each variable should adjust to partially restore the equilibrium relation for the supply of mushrooms. In the estimated supply function, what we should expect is that the value of the $E C T$ is equal to zero (although some random deviations could exist).

In Equation (2), we expect a positive change in mushroom prices to induce a negative change in mushroom harvesting, all other things being equal; that is, $\beta_{12}, \beta_{13}, \beta_{14}, \beta_{15} \leq 0$. We also expect a positive change in mushroom harvesting to induce a negative change in mushroom prices, all other things being equal; that is, $\beta_{22}, \beta_{23}, \beta_{24}, \beta_{25} \leq 0$. The expected signs for $\beta_{16}, \beta_{17}, \beta_{26}$, and $\beta_{27}$ are a priori uncertain.

The combined model in the above equation is called a VEC model. In our mushroom supply VEC model, past values of the error correction term $\left(E C T_{t-1}\right)$ help to predict future values of changes in mushroom harvesting $\left(\Delta\left(\ln \left(\right.\right.\right.$ lactkg $\left.\left._{t-1}\right)\right), \Delta\left(\ln \left(\right.\right.$ lactkg $\left.\left._{t-2}\right)\right)$, and changes in mushroom prices $\left(\Delta \ln \left(\right.\right.$ lactprt $\left._{t-1}\right)$ and $\Delta \ln \left(\right.$ lactkg $\left.\left._{t-2}\right)\right)$. The coefficients of the $E C T_{t-1}$ capture the speed of adjustment back towards the cointegrating equilibrium path, and it should be expected that the sign of the coefficient $\beta$ should be negative. So, if markets behave properly, ECT should be equal to zero, and the main consequence of a positive change in production will be a positive change in prices, and vice versa. Finally, regarding the specification and diagnostic tests, serial correlation, normality, and heteroskedasticity tests are calculated. We have also implemented the VEC Granger causality/block exogeneity Wald test in order to examine the causal effect between mushroom harvesting and mushroom prices. Definitions and brief descriptions of the applied tests can be found in the Appendix. 


\section{Results}

\subsection{Descriptive Statistics and Unit Root Tests}

First, descriptive statistics of the variables are presented in Table 2.

Table 2. Descriptive statistics.

\begin{tabular}{cccccc}
\hline & & Mean \pm Std. dev. & Median & Maximum & Minimum \\
\hline lactkg & $(\mathrm{kg})$ & $8.938 \pm 1.326$ & 9.133 & 11.157 & 3.912 \\
lactpr & $(€ / \mathrm{kg})$ & $2.212 \pm 0.555$ & 2.342 & 3.258 & 0.955 \\
tmed & $\left({ }^{\circ} \mathrm{C}\right)$ & $11.540 \pm 5.256$ & 11.450 & 23.220 & 1.980 \\
tmin & $\left({ }^{\circ} \mathrm{C}\right)$ & $3.395 \pm 4.748$ & 3.100 & 13.500 & -6.500 \\
rainfm & $(\mathrm{mm})$ & $2.164 \pm 1.987$ & 1.510 & 7.890 & 0.020 \\
rainfw & $(\mathrm{mm})$ & $3.246 \pm 2.981$ & 2.265 & 11.835 & 0.030 \\
rainfs & & $0.394 \pm 0.216$ & 0.361 & 1.000 & 0.000 \\
rainfpy & & $0.530 \pm 0.502$ & 1.000 & 1.000 & 0.000 \\
pet & $(\mathrm{mm})$ & $15.103 \pm 13.847$ & 10.450 & 55.220 & 0.140 \\
diff & $(\mathrm{mm})$ & $11.857 \pm 7.912$ & 8.185 & 43.385 & 0.110 \\
dlactprw1 & $(€ / \mathrm{kg})$ & $10.501 \pm 5.191$ & 10.400 & 26.000 & 2.600 \\
dlactprw2 & $(€ / \mathrm{kg})$ & $10.509 \pm 5.195$ & 10.400 & 26.000 & 2.600 \\
\hline We
\end{tabular}

We made 100 observations for all the variables; lactkg and lactpr are in logs; Std. dev. = stand deviation.

Results obtained from ADF and PP tests indicate that variables lactkg and lactpr are non-stationary in their levels, but become stationary after taking the first difference (Table 3). Nevertheless, the reliability of these results is low, and these results should be compared to more robust tests, the results of which should be valid even if the error term is not independent and identically distributed. This is the reason why the KPSS test was also applied. Results of the KPSS test indicate that both the mean and variance of these variables are stationary.

Table 3. Unit root tests.

\begin{tabular}{cccc}
\hline & ADF Test & PP Test & KPSS Test \\
\hline $\ln$ (lactkg) & $-4.217^{* * *}$ & $-4.304^{* * *}$ & 0.144 \\
$\Delta \ln ($ lactkg) & $-11.515^{* * *}$ & $-11.857^{* * *}$ & 0.046 \\
$\ln$ (lactpr) & $-3.841^{* *}$ & $-3.814^{* *}$ & 0.168 \\
$\Delta \ln ($ lactpr) & $-11.442^{* * *}$ & $-11.811^{* * *}$ & 0.051 \\
\hline
\end{tabular}

${ }^{* * *}$ Significant at $0.01 ;{ }^{* *}$ Significant at 0.05 .

\subsection{Cointegration Test}

Both the trace test and the eigenvalue test indicated the existence of one cointegrated relationship between the price of mushrooms and mushroom harvesting at a $5 \%$ level of significance (Table 4). This result suggests that there is one cointegrating relationship between mushroom harvesting and mushroom prices. This is relevant because the relationship between mushroom harvesting and price allows for an interpretation of the cointegrating vector as a mycological price permanent relationship. 
Table 4. Trace test and eigenvalue test.

\begin{tabular}{|c|c|c|c|c|}
\hline \multicolumn{5}{|l|}{ Trace Test } \\
\hline & Eigenvalue & Trace stats & 0.05 critical value & Probability ** \\
\hline None $\left.{ }^{*}\right)$ & 0.118 & 38.858 & $12.321 *$ & 0.0523 \\
\hline At most 1 & 0.0006 & 0.056 & 4.13 & 0.846 \\
\hline \multicolumn{5}{|c|}{ Maximum eigenvalue test } \\
\hline & Eigenvalue & Trace stast & 0.05 critical value & Probability ** \\
\hline None(*) & 0.118 & 12.15 & $11.225 *$ & 0.0343 \\
\hline At most 1 & 0.0006 & 0.056 & 4.13 & 0.846 \\
\hline
\end{tabular}

* Significant at the 0.05 level; ** MacKinnon-Haug-Michelis (1999) $p$-values.

\subsection{Cointegration Equation}

Table 5 presents the cointegrating equation results for the period 2002-2007. Results indicate that there is a cointegrating relationship between mushroom prices and mushroom harvesting. Coefficients in the cointegrated equation are statistically significant at the $1 \%$ level. The variable related to mushroom supply harvesting (lactkg) is statistically significant at the $1 \%$ level, and is positively related to prices (as we should expect from a supply function). The long-term elasticity in the mean of prices with respect to mushroom harvesting is equal to 0.799 (Table 5). That is, in the long run, whenever prices of Lactarius deliciosus increase by $1 \%$, supplied harvesting should also increase by $0.799 \%$.

Table 5. Cointegrating equation.

\begin{tabular}{lccc}
\hline & Coefficient & $\boldsymbol{t}$ Value & Elasticity at the Mean \\
\hline $\ln$ (lactpr) & 1 & & \\
$\ln ($ lactkg) & 0.31 & $9.231^{* * *}$ & 0.799 \\
\hline \multicolumn{4}{c}{${ }^{* * *}$ Significant at 0.01.}
\end{tabular}

The value of the $F$-test is high for both models (Table 6 ), and the hypothesis that the model is not significant is clearly rejected at the $1 \%$ significant level. We could say that, overall, the fitted VEC model performs well. However, in the VEC model, coefficients for the ECT are negative (Model 1) and positive (Model 2). In Model 1, the value of the ECT coefficient is -0.086 (Table 6). This indicates that $8.6 \%$ of this disequilibrium is corrected in one week (given that we are working with weekly data). Nevertheless, the sign for the ECT in Model 2 is positive, and this implies an explosive behavior of producers when the price of mushroom rises. An important point in the model is that the significance of past values (both of prices and harvesting) in determining the present values is rather small, and only prices and harvesting with the lag of one week appear to be significant in the model (see Model 2 in Table 6). In Model 1, the variable for rain (rainfm) appears to be weakly significant (10\% significance level), and presents a negative influence on changes in prices. In Model 2, the variable for temperature (tmed) presents a positive effect on harvesting changes.

In Model 1, all coefficients (both of lagged harvesting and lagged prices) are negative, and the same behavior can be found in Model 2. This indicates a correction for prices that are too high, and for an excess of harvesting in the market in both cases. In Model 1, the influence of the changes in prices for the previous week is clearly significant (at a 1\% significance level), and also for changes in the previous 
week, although only at a 10\% significance level. We can find a similar performance in Model 2 for changes in mushroom harvesting, which is highly determined both by changes in harvesting and prices in the previous week.

Table 6. Vector error correction estimates.

\begin{tabular}{lll}
\hline & Model 1 & Model 2 \\
\hline$E C T$ & $\Delta(\ln ($ lactpr $))$ & $\Delta(\ln ($ lactkg $))$ \\
$t$ & -0.086 & 0.499 \\
$\Delta\left(\ln (\text { lactkg })_{t-1}\right)$ & $-9.231^{* *}$ & $3.913^{* *}$ \\
$t$ & -0.185 & -0.619 \\
$\Delta\left(\ln (\text { lactkg })_{t-2}\right)$ & $-1.788^{*}$ & $-2.158^{* *}$ \\
$t$ & -0.076 & -0.107 \\
$\Delta\left(\ln (\text { lactpr })_{t-1}\right)$ & -0.772 & -0.413 \\
$t$ & -0.177 & -0.236 \\
$\Delta\left(\ln (\text { lactpr })_{t-2}\right)$ & $-4.783^{* *}$ & $-2.999^{* *}$ \\
$t$ & -0.038 & -0.136 \\
rainfm & -0.944 & -1.269 \\
$t$ & -0.104 & 0.105 \\
$t$ tmed & $-1.66^{*}$ & 0.627 \\
$t$ & -0.003 & 0.605 \\
Adj $R$-squared & -0.405 & $3.07^{* *}$ \\
Sum sq. Resid. & 0.208 & 0.176 \\
S.E. equation & 11.787 & 83.01 \\
$F$-statistics & 0.362 & 0.96 \\
log likelihood & $5.209^{* *}$ & $4.426^{* *}$ \\
Mean dependent & -35.415 & -130.083 \\
Standard Deviation Dependent & 0.003 & -0.018 \\
\hline
\end{tabular}

$E C T_{t-1}=$ lactpr $_{t-1}=$ Blactpr $_{t-1}{ }^{* *}$ Significant at $0.01 ;{ }^{*}$ Significant at 0.10.

Once evidence of cointegration is obtained, we have also calculated the Granger causality test (Table 7). The Granger test indicated that causality is one directional and, therefore, that mushroom supply creates its own demand.

Regarding the specification and diagnostic tests, serial correlation, normality, and heteroskedasticity tests are performed. The Lagrange multiplier (LM) test is used to test for the existence of serial correlation in the residuals, and no evidence of serial correlation can be found at a $99 \%$ significance level. The White test indicates the absence of heteroskedasticity. Nevertheless, the Jarque-Bera test presents an unexpected result and rejects the hypothesis of normality (Table 8). Two main reasons should be considered to evaluate this result. First, VEC models can be considered to be a set of regressions, and therefore, we could get highly significant Jarque-Bera values even if the residuals were not far from normality. Second, the size of the sample (100 observations), although not small, could hardly be considered asymptotical, and therefore, as suggested by [47], this test may provide a poor approximation. 
Table 7. Granger causality tests. Short-run causality between prices and harvesting.

\begin{tabular}{ll}
\hline & $\boldsymbol{F}$ Statistic \\
\hline Hypothesis: Harvesting (lactkg) does not cause price (lactpr) & \\
\hline 1 lag & $28.131^{* * *}$ \\
2 lag & $115.437^{* * *}$ \\
3 lag & $10.1604^{* * *}$ \\
4 lag & $8.118^{* * *}$ \\
5 lag & $6.189^{* * *}$ \\
\hline Hypothesis: Price (lactpr) does not cause harvesting (lactkg) \\
\hline 1 lag & 0.017 \\
2 lag & 1.296 \\
3 lag & 0.865 \\
4 lag & 0.591 \\
\hline
\end{tabular}

${ }^{* * *}$ Significant at 0.01 .

Table 8. Specification and diagnostic tests.

\begin{tabular}{lll}
\hline Lagrange Multiplier Test of Serial Correlation in the Residuals & Jarque-Bera & White's Test \\
\hline $20.849^{* * *}$ & $99.162^{* *}$ & $36.001^{*}$ \\
\hline & ${ }^{* * *}$ No serial correlation $1 \% ;{ }^{* *}$ Residuals are not normal $1 \% ;{ }^{*}$ No heteroskedastity $5 \%$.
\end{tabular}

Evidence of cointegration implies the existence of causality, at least in one direction. However, cointegration does not indicate the direction of the causal relationship. Therefore, in order to shed light on the direction of causality, we have also calculated the VEC Granger causality/block exogeneity Wald test and the null hypothesis of VEC (Table 9). Granger block exogeneity is clearly rejected at the 99\% significance level for the price equation, but only at the $60 \%$ level for the harvesting equation. This suggests very weak causality effects from mushroom prices towards mushroom harvesting; however, the evidence for harvesting determining the price of mushrooms is much more powerful.

Table 9. Granger causality tests. VEC Granger causality/block exogeneity Wald tests.

\begin{tabular}{|c|c|c|}
\hline \multicolumn{3}{|c|}{ Dependent Variable: $\Delta$ (lactkg) } \\
\hline$\Delta(\ln ($ lactpr $))$ & $\begin{array}{c}\text { Chi-square } \\
4.694^{*}\end{array}$ & $\begin{array}{l}\text { Prob. } \\
0.096\end{array}$ \\
\hline \multicolumn{3}{|c|}{ Dependent Variable: $\Delta$ (lactpr) } \\
\hline$\Delta(\ln ($ lactkg $))$ & $\begin{array}{l}\text { Chi-square } \\
22.905^{* * *}\end{array}$ & $\begin{array}{l}\text { Prob. } \\
0.001\end{array}$ \\
\hline
\end{tabular}

\section{Discussion}

In this work we have attempted to define a supply model for one of the five top-selling edible wild mushrooms [5], using as a starting point information that is generated not at a local level, but at a central market level. In different parts of the world, edible mycorrhizal fungi such as the saffron milk cap are being increasingly cultivated in suitable plantation forests [48]; however, the data in this study were not 
directly obtained from these kinds of forest systems. On the other hand, we reiterate that in this study the supply of wild edible mushrooms was addressed only in terms of the mushroom harvests that are sold in a central market; recreational mushroom picking was not considered in the supply function, despite the importance of this kind of activity in many rural communities [6].

In the paper, connections between mushroom harvesting and the behavior of explanatory variables in regard to a mushroom market (mainly climatic factors) are briefly explained. The results obtained are mostly those expected for some variables. For example, in the case of rainfall, the sign of the relationship that we found from our data is predictable, i.e., positive, and agrees with the results of several studies made at a forest level [49]. Nevertheless, other variables commonly related to rainfall appear to be weakly significant.

An important issue when approaching our model is related to the possibility of storing fresh mushrooms. Specifically, we are assuming a market for wild mushrooms without restricting products to any type of industrial process for their commercialization. Under these conditions, producers' knowledge of the markets needs to be continuously updated in order to make decisions with any probability of profit. In our case, this implies that there could only exist a minimal delay between the time in which the decision to bring mushroom harvesting to Mercabarna is taken, and the time to reach the market. These kinds of events could be represented by the error correction terms in the VEC model.

The quality of the indicators to represent the meteorological variables is a very pertinent factor when estimating a mushroom supply function. In this paper weekly data is used, but empirical evidence could be improved with daily data. Regarding some of the other variables in the model, the mean temperature indicates a positive relationship with the saffron milk cap supply. So, increases in the mean temperature in the different sites where it is assumed that these mushrooms have been picked would increase the amount of mushrooms placed on sale. The literature presents cases in which this hypothesis is confirmed [26], but in the particular case of the saffron milk cap, some studies done in Spain do not show any significant relationship between the yield of this mushroom and temperature [39], except that the arrival of the winter frosts limits their yield [50]. Other authors have found correlations among mushroom yields and temperatures, although the sign of the correlations, whether positive [51] or negative [52], is not clear. It seems that a definitive conclusion in the literature regarding the influence of temperature on the yield of edible wild mushrooms does not exist.

Also, given that no conclusive statistics on the different qualities of the saffron milk caps in Mercabarna currently exist, it was not possible to consider mushroom prices that incorporate the attribute of mushroom quality. Other interesting variables, such as the labor costs for mushroom pickers, technological costs, or those related to the relevance of human capital in mushroom activities (an attribute that is certainly relevant for professional mushroom pickers), were not considered because of the lack of available information and the enormous difficulties in obtaining this data. Accordingly, in many studies the costs derived from mushroom picking were not assumed [53,54].

Another potential extension of this work could be to simulate the effects on saffron milk cap mushroom supply prices that might appear from changes in rainfall and temperature. Such effects can only be estimated from a long time series, while this data was obtained from changes in harvesting at a very local level. 


\section{Conclusions}

The methodology proposed in this paper allows for the statistical estimation of a mushroom supply function considering the eventual differences in the behavior of mushroom markets, both in the short term and in the long run. Therefore, this method improves our ability to explain the way in which the mushroom markets are able to correct deviations from the expected behavior of mushroom collectors.

The estimated model allows for differentiation of the relevance not only of conventional variables (such as prices and collected mushroom harvest), but also of meteorological variables. From this empirical analysis we could induce that mushroom markets are mainly determined by mushroom collectors' behavior, although in the long run a double causality seems to exist between the mushroom collectors' harvests and prices.

\section{Acknowledgments}

Forestry engineer D. Ignacio Rivero has been a great help in the processing of the climatic data. Two professors at the Technical University of Madrid, D. José Carlos Robredo and D. José Alfonso Dominguez Núñez, have contributed very useful data and comments for this work. The authors are also grateful to AEMET (Spanish National Meteorological Agency) for having supplied the climatic data. We also thank Josep Faura (Mercabarna) for useful data and comments. In addition, we want to thank the three anonymous reviewers for helpful comments. The work of Oscar Alfranca and Luis Diaz-Balteiro was funded by the Ministry of Economy and Competitiveness (Project AGL2011-2585). Also, thanks are given to Diana Badder and PRS for editing the English.

\section{Author Contributions}

Óscar Alfranca carried out the econometric models and wrote the manuscript. Roberto Voces compiled mushroom data and wrote the manuscript. Luis Diaz-Balteiro coordinated the supply of data and wrote the manuscript.

\section{Conflicts of Interest}

The authors declare no conflict of interest.

\section{Appendix}

\section{A. Elasticities in the Mushroom Supply Model: A Description of some Methodological Aspects}

In this section, a brief explanation is given to justify the fact that coefficients in a Cobb-Douglas function can be assimilated to elasticities. Our mushroom supply could be represented with a Cobb-Douglas function such as:

$$
\text { lactkg }=S(\text { lactpr })=\beta \text { lactpr }{ }^{\alpha_{1}}
$$

One important problem in this function is that changes in supplied harvesting are sensitive to the units in which lactpr, rainfm, and tmed are measured. Now, we will prove that the coefficients in this function can be assimilated with elasticity values. 
If we apply logs to this function, the new expression is:

$$
\ln (\text { lactkg })=\ln \beta+\alpha_{1} \ln (\text { lactpr }) \text {. }
$$

In this function, if it is the case that:

$$
\frac{\% \Delta \ln (\text { lactkg })}{\% \Delta \ln (\text { lactpr })}=\frac{\partial \ln (\text { lactkg })}{\partial \ln (\text { lactpr })}=\alpha_{1}
$$

then

$$
\frac{\partial \ln (\text { lactkg })}{\partial \ln (\text { lactpr })} \cdot \frac{\% \Delta \ln (\text { lactpr })}{\% \Delta \ln (\text { lactkg })}=\alpha_{1} \text {. }
$$

From this, we can perfectly assume $\alpha_{1}$ is the price elasticity at the mean of mushroom harvesting. This method could be applied to all variables in the mushroom supply function.

\section{B. Mushroom Supply Model: A Description of some Methodological Aspects}

In this section, the statistical contrasts that are applied to estimate the mycological supply are briefly introduced. Thus, in order to estimate the mycological supply function, we have followed a process in which several hypotheses related to the behavior of the mycological supply are considered. In this section, these hypotheses are tested. So, we test for unit roots, cointegration, and causality. Now we present these tests.

\section{B.1. Stationarity and Unit Root Tests}

A time series is said to be stationary when it satisfies these conditions: constant mean and variance, and finite and constant covariance for all periods across time. If a time series has a unit root, then it shows a systematic pattern in its movement. This movement is a trend. This could be the case for some price time series in mushroom prices.

We begin by describing three unit root tests: the ADF test, the PP test, and the KPSS test. The ADF test and the PP test treat the non-stationary as a null hypothesis, while the KPSS test treats the stationary series under consideration as a null hypothesis. The KPSS test considers the case of a general error process, and therefore modifies the test statistic (as in $[55,56]$ ). They then derive the asymptotic distribution of the modified statistic and tabulate the critical values by simulation [57]. The choice of the KPSS test to complement the widely used ADF and PP tests is motivated by the argument that tests designed on the basis of the null that a series is difference stationary. The order of integration is the number of differencing operations it takes to make a series stationary. In our case, the price series is said to be integrated of order 1 , if lactpr $_{t}-$ lactpr $_{t-1}=u_{t}$, where $u_{t}$ is a random disturbance term.

\section{B.2. Cointegration Tests}

The Johansen procedure leads to two test statistics for cointegration: the trace and the eigenvalue. The trace tests the hypothesis that there are at most $r$ cointegrating vectors. The eigenvalue tests the hypothesis that there are $r+1$ cointegrating vectors versus the hypothesis that there are $r$ cointegrating vectors. Even the fact that two test statistics exist suggests that the inferences might be only slightly 
different, we perform both tests because the power of the trace test is relatively low. Once we have tested the existence of a cointegral relationship between mushroom prices and mushroom harvesting, we will estimate a VEC model. From this, we determine the adjustment coefficients and the eventual incidence of exogenous variables (such as those related to climate) on the mushroom market mechanism. Some author refers to a variable as exogenous with respect to a particular parameter if knowledge of the process generating the exogenous variable contains no information about the parameter [58]. On the other hand, a variable is said to be endogenous when there is a correlation between the variable and the error term. The other fundamental assumption for a supply function is that price and harvesting are positively related. It is essential to point out that the validity of cointegration rules out the existence of spurious correlation. We have also implemented Granger causality tests in order to examine the causal effects between lagged mushroom harvesting and mushroom prices in the short term, using the Wald test.

The Lagrange multiplier (LM) test is calculated to test for the existence of serial correlation in the residuals. The White's test is calculated to test the existence of heteroskedasticity and the Jarque-Bera test is calculated to test for normality.

\section{B.3. VEC Models}

In VEC models the cointegration rank shows the number of cointegrating vectors. In our case, the VEC mushroom supply function is formed of two vectors: one for mushroom prices and another for mushroom harvesting. In both equations in the estimated VEC model, not only the cointegrating variables are considered, but also two external variables: temperature and rain, which are useful to describe the adjustment process in markets (in this paper, the weekly changes).

Regarding the specification and diagnostic tests, serial correlation, normality, and heteroskedasticity tests are performed. The Lagrange multiplier (LM) test is used to test for the existence of serial correlation in the residuals. The White's test is calculated to test the existence of heteroskedasticity and the Jarque-Bera test is calculated to test for normality. We have also implemented the VEC Granger causality/block exogeneity Wald test in order to examine the causal effect between mushroom harvesting and mushroom prices, using the methodology of Granger causality vector error correction.

The VEC Granger causality/block exogeneity Wald test is calculated because with this test we can test the direction of causality in VEC models in the long run. In this test the null hypotheses to test are "mushroom prices cause mushroom harvesting", "mushroom harvesting causes mushroom prices", and the possibility that a bidirectional causality exists between the variables.

\section{References}

1. Lelley, J.I. Modern applications and marketing of useful mushrooms. Int. J. Med. Mushrooms 2005, 7, 39-47.

2. Pettenella, D.; Secco, L.; Maso, D. NWFP \& S marketing: Lessons learned and new development paths from case studies in some European countries. Small Scale For. 2007, 6, 373-390

3. Heilmann-Clausen, J.; Barron, E.S.; Boddy, L.; Dahlberg, A.; Griffith, G.W.; Nordén, J.; Ovaskainen, O.; Perini, C.; Senn-Irlet, B.; Halme, P. A fungal perspective on conservation biology. Conserv. Biol. 2015, 29, 61-68. 
4. Zotti, M.; Persiani, A.M.; Ambrosio, E.; Vizzini, A. Macrofungi as ecosystem resources: Conservation versus exploitation. Plant Biosyst. 2013, 147, 219-225.

5. Peintner, U.; Schwarz, S.; Mešić, A.; Moreau, P.-A.; Moreno, G.; Saviuc, P. Mycophilic or mycophobic? Legislation and guidelines on wild mushroom commerce reveal different consumption behaviour in European countries. PLoS ONE 2013, 8, e63926.

6. Donnini, D.; Gargano, M.L.; Perini, C.; Savino, E.; Murat, C.; Di Piazza, S.; Altobelli, E.; Salerni, E.; Rubini, A.; Rana, G.L.; et al. Wild and cultivated mushrooms as a model of sustainable development. Plant Biosyst. 2013, 147, 226-236.

7. Azul, A.M.; Nunes, J.; Ferreira, I.; Coello, A.S.; Veríssimo, P.; Trovão, J.; Campos, A.; Castro, P.; Freitas, H. Valuing native ectomycorrhizal fungi as a Mediterranean forestry component for sustainable and innovative solutions. Botany 2014, 92, 161-171.

8. Voces, R.; Diaz-Balteiro, L.; Alfranca, O. Demand for wild edible mushrooms. The case of Lactarius deliciosus in Barcelona (Spain). J. For. Econ. 2012, 18, 47-60.

9. Bonet, J.A.; González-Olabarría, J.R. Mushroom production as an alternative for rural development in a forested mountainous area. J. Mt. Sci. 2014, 11, 535-543.

10. Keca, L.J.; Keca, N.; Rekola, M. Value chains of Serbian non-wood forest products. Int. For. Rev. 2013, 15, 315-335.

11. Diaz-Balteiro, L.; Alfranca, O.; Voces, R. Mercado de Lactarius deliciosus. Modelización de la oferta en España. ITEA 2013, 109, 370-389.

12. Te Velde, D.; Rushton, J.; Schreckenberg, K.; Marshall, E.; Eduard, F.; Newton, A.; Arancibia, E. Entrepreneurship in value chains of non-timber forest products. For. Policy Econ. 2006, 8, $725-741$.

13. Diaz-Balteiro, L.; Romero, C. Valuation of environmental goods: A shadow value perspective. Ecol. Econ. 2008, 64, 517-520.

14. Cai, M.; Pettenella, D.; Vidale, E. Income generation from wild mushrooms in marginal rural areas. For. Policy Econ. 2011, 13, 221-226.

15. Martínez de Aragón, J.; Riera, P.; Giergiczny, M.; Colinas, C. Value of wild mushroom picking as an environmental service. For. Policy Econ. 2011, 13, 419-424.

16. Last, F.; Mason, R.; Smith, R.; Pelham, J.; Shetty, K.; Hussain, A. Factors affecting the production of fruitbodies of Amanita muscaria in plantations of Pinus patula. Proc. Indian Acad. Sci. 1981, 90, 91-98.

17. Pinna, S.; Gévry, M.-F.; Sirois, L. Factors influencing fructification phenology of edible mushrooms in a boreal mixed forest of Eastern Canada. For. Ecol. Manag. 2010, 260, 294-301.

18. Ágreda, T.; Cisneros, O.; Águeda, B.; Fernández-Toirán, L. Age class influence on the yield of edible fungi in a managed Mediterranean forest. Mycorrhiza 2014, 24, 143-152.

19. Shaw, P.J.A.; Kibby, G.; Mayer, J. Effects of thinning treatment on an ectomycorrhizal succession under Scots pine. Mycol. Res. 2003, 107, 317-328.

20. Egli, S.; Ayer, F.; Peter, M.; Eilmann, B.; Rigling, A. Is forest mushroom productivity driven by tree growth? Results from a thinning experiment. Ann. For. Sci. 2010, 67, 509.

21. Barroetaveña, C.; La Manna, L.; Alonso, M.V. Variables affecting Suillus luteus fructification in ponderosa pine plantations of Patagonia (Argentina). For. Ecol. Manag. 2008, 256, 1868-1874. 
22. Kucuker, D.M.; Baskent, E.Z. Spatial prediction of Lactarius deliciosus and Lactarius salmonicolor mushroom distribution with logistic regression models in the Kızılcasu Planning Unit, Turkey. Mycorrhiza 2015, 25, 1-11.

23. Ohenoja, E. Effect of Weather Conditions on the Larger Fungiat Different Forest Sites in Northern Finland in 1976-1988. Ph.D. Thesis, University of Oulu, Oulu, Finland, 1993.

24. Pilz, D.; Molina, R. Commercial harvests of edible nushrooms from the forests of the Pacific Northwest United States: Issues, management, and monitoring for sustainability. For. Ecol. Manag. 2002, 155, 3-16.

25. Ogaya, R.; Peñuelas, J. Decreased mushroom production in a holm oak forest in response to an experimental drought. Forestry 2005, 78, 279-283.

26. Straatsma, G.; Ayer, F.; Egli, S. Species richness, abundance, and phenology of fungal fruit bodies over 21 years in a Swiss forest plot. Mycol. Res. 2001, 105, 515-523.

27. Salerni, E.; Laganà, A.; Perini, C.; Loppi, S.; De Dominicis, V. Effects of temperature and rainfall on fruiting of macrofungi in oak forests of the Mediterranean area. Israel J. Plant Sci. 2002, 50, 189-198.

28. Krebs, C.J.; Carrier, P.; Boutin, S.; Boonstra, R.; Hofer, E. Mushroom crops in relation to weather in the southwestern Yukon. Can. J. Bot. 2008, 86, 1497-1502.

29. Laganà, A.; Angiolini, C.; Loppi, S.; Salerni, E.; Perini, C.; Barluzzi, C.; De Dominicis, V. Periodicity, fluctuations and successions of macrofungi in fir forest (Abies alba Miller) in Tuscany, Italy. For. Ecol. Manag. 2002, 169, 187-202.

30. Bonet, J.A.; Palahí, M.; Colinas, C.; Pukkala, T.; Fischer, C.R.; Miina, J.; Martínez de Aragón, J. Modelling the production and speciesrichness of wild mushrooms in pine forest of the Central Pyrenees in northeastern Spain. Can. J. For. Res. 2010, 40, 347-356.

31. De-Miguel, S.; Bonet, J.A.; Pukkala, T.; Martínez de Aragón, J. Impact of forest management intensity on landscape-level mushrooms productivity: A regional model-based scenario analysis. For. Ecol. Manag. 2014, 330, 218-227.

32. Ohenoja, E.; Koistinen, R. Fruit body production of larger fungi in Finland. Ann. Bot. Fenn. 1984, 21, 357-366.

33. Schulp, C.J.E.; Thuiller, W.; Verburg, P.H. Wild food in Europe: A synthesis of knowledge and data of terrestrial wild food as an ecosystem service. Ecol. Econ. 2014, 105, 292-305.

34. De Román, M.; Boa, E. The marketing of Lactarius deliciosus in northern Spain. Econ. Bot. 2006, 60, 284-290.

35. Bonet, J.A.; Pukkala, T.; Fischer, C.R.; Palahí, M.; de Aragón, J.M.; Colinas, C. Empirical models for predicting the production of wild mushrooms in Scots pine (Pinus sylvestris L.) forests in the Central Pyrenees. Ann. For. Sci. 2008, 65, 2.

36. Oria de Rueda, J.A. Hongos y Setas. Tesoro de Nuestros Montes, 2nd ed.; Ed. Cálamo: Palencia, Spain, 2007.

37. Domínguez Núñez, J.A.; López Leiva, C.; Rodríguez Barreal, J.A.; Saiz de Omeñaca, J.A. Caracterización de rodales productores de Lactarius deliciosus (L.: Fr.) S.F. Gray y Lactarius sanguifluus (Paulet ex Fr.) Fr. en la Comunidad Valenciana. Bol. Soc. Micol. Valencia. 2008, 13, $2-18$. 
38. Rubinstein, A. Lecture Notes in Microeconomic Theory; Princeton University Press: Princeton, NJ, USA, 2006.

39. Martínez de Aragón, J.; Bonet, J.A.; Fischer, C.R.; Colinas, C. Productivity of ectomycorrhizal and selected edible saprotrophic fungi in pine forests of the pre-Pyrenees mountains, Spain: Predictive equations for forest management of mycological resources. For. Ecol. Manag. 2007, 252, 239-256.

40. Palahi, M.; Pukkala, T.; Bonet, J.A.; Colinas, C.; Fischer, C.R.; Martínez de Aragón, J. Effect of the inclusion of mushroom values on the optimal management of even-aged pine stands of Catalonia. For. Sci. 2009, 55, 503-551.

41. Kranabetter, J.; Kroeger, P. Ectomycorrhizal mushroom response to partial cutting in a western hemlock/western redcedar forest. Can. J. For. Res. 2001, 31, 978-987.

42. Thornthwaite, C.W. An approach toward a rational classification of climate. Geogr. Rev. 1948, 38, 55-94.

43. Hoover, K.D.; Perez, S.J. Data minning reconsidered: Encompassing and the general-to-specific approach to specification search. Econom. J. 1999, 2, 167-191.

44. Hendry, D.F.; Doornik, J.A. Empirical Model Discovery and Theory Evaluation. Available online: http://www.jstor.org/stable/j.ctt9qf9km (accessed on 23 March 2015).

45. Hendry, D.F.; Krolzig, H.M. We ran one regression. Oxf. B Econ. Stat. 2004, 66, 799-810.

46. Sarker, D.; Das, N. Efficiency of Market Behaviour of NTFPs for Households under JFMP: A Case Study in West Bengal. 2009. Available online: http://mpra.ub.uni-muenchen.de/14779/1/ MPRA_paper_14779.pdf (accessed on 14 May 2015).

47. Kilian, L.; Demiroglu, U. Residual-based tests for normality in autoregressions asymptotic theory and simulation evidence. J. Bus. Econ. Stat. 2000, 18, 40-50.

48. Guerin-Laguette, A.; Cummings, N.; Butler, R.C.; Willows, A. Lactarius deliciosus and Pinus radiata in New Zealand: Towards the development of innovative gourmet mushroom orchards. Mycorrhiza 2014, 24, 511-523.

49. Dahl, F.A.; Galteland, T.; Gjelsvik, R. Statistical modelling of wildwood mushroom abundance. Scand. J. For. Res. 2008, 23, 244-249.

50. Martínez-Peña, F.; Ágreda, T.; Águeda, B.; Ortega-Martínez, P.; Fernández-Toirán, L.M. Edible sporocarp production by age class in Scots pine stand in Northern Spain. Mycorrhiza 2012, 22, 167-174.

51. Martínez-Peña, F.; de-Miguel, S.; Pukkala, T.; Bonet, J.A.; Ortega-Martínez, P.; Aldea, J.; Martínez de Aragón, J. Yield models for ectomycorrhizal mushrooms in Pinus sylvestris forests with special focus on Boletus edulis and Lactarius group deliciosus. For. Ecol. Manag. 2012, 282, 63-69.

52. De la Varga, H.; Águeda, B.; Ágreda, T.; Martínez-Peña, F.; Parladé, J.; Pera, J. Seasonal dynamics of Boletus edulis and Lactarius deliciosus extraradical mycelium in pine forests of central Spain. Mycorrhiza 2013, 23, 391-402.

53. Aldea, J.; Martínez-Peña, F.; Diaz-Balteiro, L. Integration of fungal production in forest management using a multi-criteria method. Eur. J. For. Res. 2012, 131, 1991-2003.

54. Aldea, J.; Martínez-Peña, F.; Romero, C.; Diaz-Balteiro, L. Participatory goal programming in forest management: An application integrating several ecosystem services. Forests 2014, 5, 3352-3371.

55. Phillips, P.C.B. Time series regression with unit root. Econometrica 1987, 55, 227-301. 
56. Phillips, P.C.B.; Perron, P. Testing for unit roots in time series regression. Biometrika 1988, 75, 335-346.

57. Maddala, G.S.; Kim, I.-M. Unit Roots, Cointegration, and Structural Change; Cambridge University Press: Cambridge, UK, 1998.

58. Engle, R.F.; Hendry, D.F.; Richard, J.F. Exogeneity. Econometrica 1983, 51, 277-304.

(C) 2015 by the authors; licensee MDPI, Basel, Switzerland. This article is an open access article distributed under the terms and conditions of the Creative Commons Attribution license (http://creativecommons.org/licenses/by/4.0/). 